\title{
IOM and DHHS Meeting on Making Clinical Practice Guidelines Appropriate for Patients with Multiple Chronic Conditions
}

\author{
Richard A. Goodman, MD, $M P H^{1-3}$ \\ Cyntbia Boyd, MD, MPH \\ Mary E. Tinetti, $M D^{5}$ \\ Isabelle Von Koborn, $M D, P b D^{6}$ \\ Anand K. Parekh, MD, MPH \\ J. Michael McGinnis, MD, MA, \\ $M P P^{7}$ \\ 'Office of the Assistant Secretary for \\ Health, US Department of Health and \\ Human Services, Washington, DC
}

${ }^{2}$ National Center for Chronic Disease Prevention and Health Promotion, Centers for Disease Control and Prevention, Atlanta, Georgia

${ }^{3}$ Division of General Medicine and Geriatrics, Emory University, Atlanta, Georgia

${ }^{4}$ Division of Geriatric Medicine and Gerontology, Johns Hopkins University, Baltimore, Maryland

${ }^{5}$ Department of Internal Medicine (Geriatrics), Yale School of Medicine, and Yale School of Public Health, New Haven,

Connecticut

${ }^{6}$ Holy Cross Health, Silver Spring, Maryland ${ }^{7}$ Institute of Medicine, Washington, DC

Conflicts of interest: Dr. Boyd was supported by the Paul Beeson Career Development Award Program (NIA K23 AG 032910 , the Jobn A. Hartford Foundation, Atlantic Pbilantbropies, the Starr Foundation, and an anonymous donor) and AHRQ R21 HS018597-01. She bas coauthored a chapter for UptoDate on multimorbidity, for which she receives a royalty. The other authors report no conflicts.

\section{CORRESPONDING AUTHOR}

Richard A. Goodman, MD

Centers for Disease Control and Prevention Mailstop K40, 4770 Buford Hwy NE

Atlanta, GA 30341

rag4@cdc.gov

\begin{abstract}
BACKGROUND The increasing prevalence of Americans with multiple (2 or more) chronic conditions raises concerns about the appropriateness and applicability of clinical practice guidelines for patient management. Most guidelines clinicians currently rely on have been designed with a single chronic condition in mind, and many such guidelines are inattentive to issues related to comorbidities.
\end{abstract}

PURPOSE In response to the need for guideline developers to address comorbidities in guidelines, the Department of Health and Human Services convened a meeting in May 2012 in partnership with the Institute of Medicine to identify principles and action options.

RESULTS Eleven principles to improve guidelines' attentiveness to the population with multiple chronic conditions were identified during the meeting. They are grouped into 3 interrelated categories: (1) principles intended to improve the stakeholder technical process for developing guidelines; (2) principles intended to strengthen content of guidelines in terms of multiple chronic conditions; and (3) principles intended to increase focus on patient-centered care.

CONCLUSION This meeting built upon previously recommended actions by identifying additional principles and options for government, guideline developers, and others to use in strengthening the applicability of clinical practice guidelines to the growing population of people with multiple chronic conditions. The suggested principles are helping professional societies to improve guidelines' attentiveness to persons with multiple chronic conditions.

Ann Fam Med 2014;256-259. doi:10.1370/afm.1646.

\section{INTRODUCTION}

1

he prevalence of comorbidities is high and increasing in Americans: one-fourth of all adults have multiple ( 2 or more) chronic conditions. ${ }^{1}$ Among older adults, the prevalence of multiple chronic conditions is at least $75 \%$. The presence of multiple conditions creates many challenges for family physicians and other clinicians, including the need to decide what evidence to use in making clinical decisions and the need to take into account patients' contexts and personal preferences in relation to clinical decision making. ${ }^{2-4}$ Clinicians are encouraged to follow evidencebased clinical practice guidelines in managing their patients' conditions, and most often they must rely on guidelines that have been designed for a single chronic condition. Most single-condition guidelines, however, are inattentive to issues related to the coexistence of other chronic conditions. . $^{5-9}$

The failure of condition-specific guidelines to address comorbidities has prompted concerns about the appropriateness of using current singlecondition guidelines in managing patients with multiple chronic conditions. To begin with, results of randomized clinical trials that evaluate medications for single target conditions but exclude individuals with comorbidities 
may not be generalizable to persons with comorbid conditions. ${ }^{5,6,8,10-13}$ Other issues include whether adherence to a medication regimen for one condition is altered by guideline-recommended treatments for other conditions and whether the increasing number of medications used simultaneously by patients with multiple conditions in accordance with multiple guidelines has net beneficial or harmful effects. ${ }^{5,6}$ Furthermore, the appropriateness of adhering to several clinical guidelines in the management of individual patients must be reconciled with each patient's preference for health care interventions and outcomes. $2,3,5,6,8,14,15$ These issues are compounded by the more general challenge of barriers to use of guidelines. ${ }^{16}$

Previous recommendations to improve clinical guidelines for managing patients with comorbidities have addressed the importance of clinical trials that include patients with the most relevant comorbidities and the most prevalent combinations of comorbidities; guidelines that address risks, benefits, and burdens associated with treatments recommended for comorbidities; guidelines that address more explicitly their applicability to, and quality of evidence for, patients with comorbidities; and education for professional societies that do not yet incorporate comorbidity into their guidelines. ${ }^{6,8,17-21}$

\section{Meeting on Multiple Chronic Conditions and Clinical Practice Guidelines}

As part of its national initiative on multiple chronic conditions, the US Department of Health and Human Services (DHHS) developed Multiple Chronic Conditions: A Strategic Framework, which includes an explicit focus on the need for clinical guideline developers to address multiple chronic conditions. ${ }^{22}$ In response to the Strategic Framework's call for action on this issue and in conjunction with the IOM, the DHHS convened a meeting of expert stakeholders in May 2012 with the goals of identifying guiding principles for clinical guidelines in the effective management of multiple chronic conditions and identifying actions that should be taken by developers and users of guidelines for people with multiple chronic conditions. ${ }^{23}$ Participants represented the DHHS, organizations that develop guidelines, and academia (see the list of IOM and DHHS meeting participants at the end of this article).

Meeting participants articulated both new and previously identified principles for including issues related to multiple chronic conditions in the guideline development process and in resultant clinical guidelines. ${ }^{7,17,24}$ These principles refine the call for guideline developers and users to address people with multiple chronic conditions as outlined in the HHS Strategic Framework and complement the IOM's standards for trustworthy guidelines and systematic reviews. ${ }^{7}$ The principles can be grouped into categories based on 3 interrelated aims.

\section{Improve the Stakeholder Technical Process for Developing Guidelines}

To better address multiple chronic conditions in clinical guidelines, (1) guideline development should harmonize or coordinate comorbidity-related contents across guidelines created by different guidelinedeveloping groups ${ }_{i}(2)$ guideline development panels should include appropriate expert representation (eg, general internal medicine, geriatrics, family medicine and other primary care practitioners) for conditions and domains other than the index condition ${ }_{i}(3)$ to the extent possible, guideline development should comport with the "Standards for Developing Trustworthy Clinical Practice Guidelines" as described in the IOM's report on "Clinical Practice Guidelines We Can Trust" ${ }^{\prime \prime, 18}$ and should adapt principles from other relevant guidance (eg, "Patient-Centered Care for Older Adults with Multiple Chronic Conditions: A Stepwise Approach from the American Geriatrics Society"). ${ }^{14}$

\section{Strengthen Substance and Content}

To strengthen guidelines' attentiveness to multiple chronic conditions, (1) guidelines should take into account factors associated with adherence as a function of the number and types of comorbid conditions present in individual patients ${ }_{i}(2)$ guidelines should explicitly prompt clinicians to consider comorbidities in addition to a guideline's index condition ( $_{i}$ ) discussion of comorbidities should be integrated into guidelines rather than addressed in supplemental sections; (4) in addition to addressing what is known about relevant comorbidities, condition-specific guidelines should concisely summarize what key information is unknown $_{i}(5)$ guidelines should call attention to and integrate preventive measures across certain index conditions, such as ischemic heart disease or heart failure, which may have implications for other conditions (eg, hypertension, diabetes, and/or depression) and to modifiable risk factors (eg, sedentary lifestyle); and (6) guidelines should address care coordination across providers and settings.

\section{Increase Focus on Patient-centeredness}

To strengthen focus on patient-centeredness, (1) guidelines should be patient-centered, supporting the care of individual patients, rather than focused solely on the management of specific conditions; and (2) because of the complexity of management plans for persons with multiple chronic conditions, the application of guidelines should take into account the need for and importance of shared decision making. 


\section{IMPLICATIONS}

The IOM and DHHS meeting built upon previously recommended actions by producing additional options for government, guideline developers, and others to use in strengthening the applicability of clinical guidelines to the growing population of individuals with multiple chronic conditions. These suggested actions can help amplify use of previous recommendations and catalyze new efforts to improve guidelines' attentiveness to the population of individuals with multiple chronic conditions. Recent examples include (1) the provision of information and education on comorbidities for use by professional societies and organizations that sponsor the development of guidelines and by guideline developers themselves; (2) engagement of the Guidelines International Network (G-I-N) in disseminating principles of guideline development for multiple chronic conditions to guideline developers; and (3) formation of partnership groups (including, for example, government and other public, non-profit, and private stakeholders) to refine approaches to addressing comorbidities in guidelines for use by societies and other organizations that develop them.

Specifically, following the IOM and DHHS meeting, several of the organizations participating in the meeting took actions that help implement the options identified during the meeting. For example, to implement the provision of information for guidelinedeveloping organizations, DHHS, through the Centers for Medicare \& Medicaid Services, provided the American College of Cardiology and American Heart Association Task Force on Clinical Guidelines with listings of the 10 most common comorbidities for selected cardiovascular index conditions in the Medicare feefor-service beneficiary population; these data were then incorporated within the updated clinical guideline on heart failure treatment published in October 2013. ${ }^{25}$ DHHS developed similar data for other organizations, including the American Society for Clinical Oncology, and helped that organization develop a template on multiple chronic conditions for use in selected guidelines. ${ }^{26}$ Also as a result of the meeting, the Guidelines Development Task Force of the American Academy of Otolaryngology-Head and Neck Surgery Foundation intensified efforts to incorporate discussion of comorbidities within the disease burden sections of guidelines produced by that organization. ${ }^{27,28}$

To further engage the Guidelines International Network, DHHS participated in a dedicated G-I-N webinar in early 2013 titled "Addressing Co-Morbidities: A Call to Action for the Clinical Practice Guidelines Community $^{\prime \prime}$ and published a call to action in the G-I-N newsletter for its members to launch a process of updating guidelines to include information on the most common comorbidities to the index conditions, to consider inviting subject-matter experts on specific comorbidities to be a part of their guidelines committees, and to partner with other professional societies that write guidelines on specific conditions. ${ }^{29}$ In late 2013, G-I-N formed a new international multimorbidity working group as a forum for considering how multimorbidity can be addressed in guidelines. ${ }^{30}$ Finally, as an interim step in promoting the formation of partnership groups, DHHS convened participants to share updates and approaches to the integration of comorbidities into guidelines, including actions such as those described above.

\section{CONCLUSIONS}

The increasing prevalence of persons with multiple chronic conditions-especially among the population of Medicare beneficiaries in whom health-care utilization indicators (eg, hospital readmissions and emergency room visits) and comorbidity-related expenditures are major cost drivers ${ }^{31}$ - is accelerating the need for improved clinical practice guidelines for patient management. DHHS, through its strategic framework on multiple chronic conditions, addressed this priority need by calling for guideline developers to deal with multiple chronic conditions in guidelines and, in a related action, by convening the 2012 meeting in partnership with IOM to identify principles and options for action steps. Given the absence of a centralizing force behind guidelines development, the collective implementation of such actions in the United States will require sustained complementary will and commitment by government and private (nonprofit) actors.

To read or post commentaries in response to this article, see it online at http://www.annfammed.org/content/12/3/256.

Key words: practice guidelines; multiple chronic conditions; comorbidities; Institute of Medicine; IOM; Department of Health and Human Services; DHHS.

Submitted November 12, 2013; submitted, revised, February 13, 2014; accepted, March 9, 2014

IOM and DHHS Meeting Participants: In addition to the authors, the following individuals participated in the meeting held at the IOM on May 29, 2012: Jayasree Basu, PhD, MBA; Nick Beard, MD; Caroline S. Blaum, MD, MS; Erica S. Breslau, PhD; Russell E. Glasgow, PhD; Mary Kane Goldstein, MD; Sheldon Greenfield, MD; Elbert Huang, MD; Norman Kahn, MD; Robert C. Kalayjian, MD; M. Sue Kirkman, MD; Howard K. Koh, MD, MPH; Jerry Krishnan, MD, PhD; Robert Kunkle, MA; Keith D. Lind, JD, MS; Shari Ling, MD; David Meyers, MD; Debjani Mukherjee, MPH; Wendy J. Nilsen, PhD; Mary Nix, MS, MT(ASCP)SBB, PMP; Robert M. Plovnick, MD, MS; Amir Qaseem, MD, PhD, MHA; Robert E. Ratner, MD; Alicia Richmond Scott, MSW; Craig Robbins, MD, MPH; Richard M. Rosenfeld, MD, MPH; Marcel Salive, MD, MPH; Betsy Schwartz; Denise Simons-Morton, MD, PhD; Mark R. Somerfield, PhD; James J. Stevermer, MD, MSPH; Katrin Uhlig, MD; Cally Vinz; and Barbara Yawn, MD, MSc, FAAFP. 
Disclaimer: The findings and conclusions in this report are those of the authors and do not necessarily represent the official position of the Centers for Disease Control and Prevention.

\section{References}

1. Ward BW, Schiller JS. Prevalence of multiple chronic conditions among US adults: estimates from the National Health Interview Survey, 2010. Prev Chronic Dis. 2013;10:E65.

2. Wyatt KA, Stuart LM, Brito JP, et al. Out of context: clinical practice guidelines and patients with multiple chronic conditions: a systematic review. Med Care. 2014; 52(Suppl 3):S92-S100.

3. Montori VM, Brito JP, Murad MH. The optimal practice of evidence-based medicine: incorporating patient preferences in practice guidelines. JAMA. 2013;310(23):2503-2504.

4. Bonds D, Boyd C, Davis M, et al. Understanding the context of health for people with multiple chronic conditions: moving from what is the matter to what matters. Ann Fam Med. 2014;12(3):260-269.

5. Tinetti ME, Bogardus ST Jr, Agostini JV. Potential pitfalls of diseasespecific guidelines for patients with multiple conditions. N Engl J Med. 2004;351(27):2870-2874.

6. Boyd CM, Darer J, Boult C, Fried LP, Boult L, Wu AW. Clinical practice guidelines and quality of care for older patients with multiple comorbid diseases: implications for pay for performance. JAMA. 2005;294(6):716-724.

7. Institute of Medicine (IOM). Clinical Practice Guidelines We Can Trust. Washington, DC: The National Academies Press; 2011.

8. Lugtenberg M, Burgers JS, Clancy C, Westert GP, Schneider EC. Current guidelines have limited applicability to patients with comorbid conditions: a systematic analysis of evidence-based guidelines. PLOS ONE. 2011;6(10):e25987. http://www. plosone.org/article/info\%3 Adoi\%2F10.1371\%2Fjournal.pone.0025987. Accessed Nov 5, 2013.

9. Shekelle P, Woolf S, Grimshaw JM, Schünemann HJ, Eccles MP. Developing clinical practice guidelines: reviewing, reporting, and publishing guidelines; updating guidelines; and the emerging issues of enhancing guideline implementability and accounting for comorbid conditions in guideline development. Implement Sci. 2012;7:62 http://www.implementationscience.com/content/7/1/62. Accessed Nov 5, 2013.

10. Van Spall HG, Toren A, Kiss A, Fowler RA. Eligibility criteria of randomized controlled trials published in high-impact general medical journals: a systematic sampling review. JAMA. 2007;297(11):12331240.

11. Jadad AR, To MJ, Emara M, Jones J. Consideration of multiple chronic diseases in randomized controlled trials. JAMA. 2011; 306(24):2670-2672.

12. Zulman DM, Sussman JB, Chen X, Cigolle CT, Blaum CS, Hayward RA. Examining the evidence: a systematic review of the inclusion and analysis of older adults in randomized controlled trials. J Gen Intern Med. 2011;26(7):783-790.

13. Boyd CM, Vollenweider D, Puhan MA. Informing evidence-based decision-making for patients with comorbidity: availability of necessary information in clinical trials for chronic diseases. PLOS ONE. 2012;7(8):e41601. http://www.plosone.org/article/info\%3Adoi\% 2F10.1371\%2Fjournal.pone.0041601. Accessed Nov 5, 2013.

14. American Geriatrics Society Expert Panel on the Care of Older Adults with Multimorbidity. Patient-centered care for older adults with multiple chronic conditions: a stepwise approach from the American Geriatrics Society. J Am Geriatr Soc. 2012;60(10):19571968. http://www.americangeriatrics.org/files/documents/MCC. stepwise.approach.pdf. Accessed Nov 5, 2013.

15. Guthrie B, Payne K, Alderson P, McMurdo ME, Mercer SW. Adapting clinical guidelines to take account of multimorbidity. BMJ. 2012; 345:e6341.
16. Pronovost PJ. Enhancing physicians' use of clinical guidelines. JAMA. 2013;310(23):2501-2502.

17. Fabbri LM, Boyd C, Boschetto P, et al.; ATS/ERS Ad Hoc Committee on Integrating and Coordinating Efforts in COPD Guideline Development. How to integrate multiple comorbidities in guideline development: article 10 in Integrating and coordinating efforts in COPD guideline development. An official ATS/ERS workshop report. [abstract]. Proc Am Thorac Soc. 2012;9(5):274-281. http://pats.atsjournals.org/content/9/5/274.

18. Uhlig K, Leff B, Kent D, et al. A framework for crafting clinical practice guidelines that are relevant to the care and management of people with multimorbidity. JGIM. 2014 Jan 18. [Epub ahead of print].

19. Boyd C. CPGs for people with multimorbidities. Presented at the IOM Committee on Standards for Developing Trustworthy Clinical Practice Guidelines meeting, on November 11, 2010, Washington, DC.

20. Boyd CM, Kent D. Evidence-based medicine and the hard problem of multimorbidity. JGIM. 2014 Jan 18. [Epub ahead of print].

21. Weiss CO, Varadhan R, Puhan M, et al. Multimorbidity and evidence generation. JGIM. 2014 Jan 18.

22. U.S. Department of Health and Human Services. Multiple chronic conditions-a strategic framework: optimum health and quality of life for individuals with multiple chronic conditions. Washington, DC. December 2010. http://www.hhs.gov/ash/initiatives/mcc/ mcc_framework.pdf. Accessed Nov 5, 2013.

23. IOM Roundtable on Multiple Chronic Conditions and Clinical Practice Guidelines. http://iom.edu/Activities/Quality/VSRT/2012-MAY-29. aspx. Accessed Nov 5, 2013.

24. Shekelle PG, Schünemann H, Woolf SH, Eccles M, Grimshaw J. 2010. State of the art of CPG development and best practice standards. In: Committee on Standards for Trustworthy Clinical Practice Guidelines.

25. Yancy CW, Jessup M, Bozkurt B, et al. 2013 ACCF/AHA Guideline for the management of heart failure: a report of the American College of Cardiology Foundation/American Heart Association Task Force on Practice Guidelines. J Am Coll Cardiol. 2013;62(16):e147-e239. http:// content. onlinejacc.org/article. aspx?articleid $=1695825$. Accessed Nov 5, 2013.

26. Lyman GH, Temin S, Edge SB, et al. Sentinel lymph node biopsy for patients with early-stage breast cancer: American Society of Clinical Oncology Clinical Practice Guideline Update. J Clin Oncol. 2014; Published online ahead of print April 7, 2014. http://jco.ascopubs. org/content/early/2014/04/03/JCO.2013.54.1177.full.pdf.

27. Guidelines Development Task Force. IOM multiple chronic conditions and clinical practice guidelines. American Academy of Otolaryngology-Head and Neck Surgery Foundation. Summer 2012 Newsletter. http://www.entnet.org/guide_lines/upload/GDTFSummer-2012-Newsletter_FINAL.pdf. Accessed Nov 5, 2013.

28. Rosenfeld RM, Shiffman RN, Robertson P. Clinical Practice Guideline Development Manua 3rd ed. A quality-driven approach for translating evidence into action. Otolaryngol Head Neck Surg. 2013;148(1S): S1-S55.

29. Parekh AK. US Department of Health and Human Services Strategic Framework on Multiple Chronic Conditions and Clinical Practice Guidelines Invited article on comorbidities. Invited article. ENGINE. June 2013; 14. http://www.g-i-n.net/document-store/engine/enginejune-2013.pdf. Accessed Feb 5, 2014.

30. Guidelines International Network (GIN). Multimorbidity. http:// www.g-i-n.net/activities/multimorbidity. Accessed Feb 5, 2014.

31. Chronic Conditions Among Medicare Beneficiaries, Chartbook, 2012 Edition. Baltimore, MD: Centers for Medicare and Medicaid Services. 2012. http://www.cms.gov/Research-Statistics-Dataand-Systems/Statistics-Trends-and-Reports/Chronic-Conditions/ Downloads/2012Chartbook.pdf. Accessed Nov 5, 2013. 